Anthropos: Jurnal Antropologi Sosial dan Budaya (Journal of Social and Cultural Anthropology)

6 (2) (2021): 151-160 DOI: https://doi.org/10.24114/antro.v6i2.18077

Anthropos: Jurnal Antropologi Sosial dan Budaya (Journal

of Social and Cultural Anthropology)

Available online http://jurnal.unimed.ac.id/2012/index.php/anthropos

\title{
Pelestarian Tradisi Buka Luwur: \\ Studi Budaya di Makam Sunan Kudus Jawa Tengah
}

\section{Preservation of Luwur Open Traditions: \\ Cultural Studies in the Tomb of Sunan Kudus, Central Java}

\author{
Moh Rosyid \\ Institut Agama Islam Negeri, Kudus, Jawa Tengah, Indonesia
}

Diterima: 13 Mei 2020; Direview: 07 Juni 2020; Disetujui: 26 Juli 2020

\begin{abstract}
Abstrak
Artikel ini bertujuan memaparkan dan memprediksi keberlanjutan tradisi buka luwur yakni kain yang melindungi makam Sunan Kudus yang diperingati dengan mengganti luwur baru dalam Tradisi Buka Luwur di Desa Kauman, Kecamatan Kota, Kudus setiap bulan Muharam/Sura. Data riset ini diperoleh penulis dengan wawancara, observasi partisipatif, dan telaah pustaka. Terkumpulnya data dianalisis dengan pendekatan sejarah. Tradisi buka luwur memiliki kekhasan yakni pembagian bubur Asura, nasi jangkrik, atraksi seni islami yang dipertunjukkan pada publik, dan penggantian luwur lama dengan luwur baru. Ragam motif luwur di Makam Sunan Kudus meliputi bunga melati, unthuk banyu, kompol, dan wiru. Oleh panitia, luwur lama dipotong-potong dan dibagikan pada warga sedesa Kauman dan tamu yang menghadiri acara Buka Luwur. Tradisi dilestarikan Pengurus Masjid alAqsha Kudus bersama warga Desa Kauman dan warga Kudus dan sekitarnya untuk menghormati jejak sejarah islamisasi yang diperankan Sunan Kudus di wilayah Kudus masa kewalian.
\end{abstract}

Kata Kunci: Tradisi, Luwur, Sunan Kudus, Lestari.

Abstract
This article describes and to prediction sustainability the tradition of buka luwur which is a cloth that protects the tomb of Sunan Kudus in Kauman Village, Kota District, Kudus every month Muharam/Sura. This research data were obtained by interview, participatory observation, and literature review. Data collection was analyzed using a historical approach. The tradition of open flexible has a characteristic that is the distribution of Asura porridge, nasi jangkrik, Islamic art attractions that are displayed to the public, and the replacement of old luwur with the new one. The ornaments of the luwur include jasmine, unthuk banyu, kompol, and pleats. By the committee, the old luwur was cut into pieces and distributed to residents of Kauman village and guests who attended Buka Luwur. This tradition is still preserved by the al-Aqsa Kudus Mosque caretaker and people of Kauman Village and the citizens of Kudus and surrounding areas to honor the traces of the history of islamization which was played by Sunan Kudus in the Kudus region during the times of unity.

Key words: Tradition, Luwur, Sunan Kudus, Sustainability.

How to Cite: Rosyid, M. (2021). Pelestarian Tradisi Buka Luwur: Studi Budaya di Makam Sunan Kudus Jawa Tengah. Anthropos: Jurnal Antropologi Sosial dan Budaya Uournal of Social and Cultural Anthropology) 6 (2): 151-160.

*Corresponding author:

E-mail:mrosyid72@yahoo.co.id

ISSN 2549-1660 (Print)

ISSN 2550-1305 (Online) 


\section{PENDAHULUAN}

Kekayaan budaya Indonesia diakui dunia sebagai karya adiluhung. Sebut saja Candi Buddha Borobudur berdiri tahun 800-an M memiliki stupa dan terdapat 2.672 panel relief. Selain itu, Candi Hindu Prambanan dibangun pertengahan abad ke-9. Candi ini memiliki candi utama yakni Brahma dan Siwa. Ada pula Situs Manusia Purba Sangiran, Sragen. Ketiganya di Jawa Tengah.

Tradisi dan kekhasannya merupakan produk budaya masyarakat yang berbudaya. Kekhasan tersebut merupakan daya perekat dilestarikannya sebuah tradisi oleh pelaku budaya. Selain itu, makna sebuah tradisi memiliki daya tarik sehingga direspon oleh komunitas budaya. Adanya makna yang khas, budaya tetap kokoh dipertahankan sebagai identitas bila dilandasai ajaran agama. Menurut Isrofah, aspek budaya dari segi nilai dapat dijadikan sebagai wadah pembentuk dan pewarna keagamaan komunitas. Keberhasilan budaya dan keagamaan bila sejalan dengan nilai yang dimiliki komunitas (Isrofah, 2018). Dakwah Sunan Kudus direspon oleh warga Kudus dengan pendekatan kultur dalam bentuk karya wayang klitik, tembang Maskumambang, Mijil, dan akulturasi budaya berupa bangunan Menara Kudus dan Masjid alAqsha (Hasanah, 2019). Pesan toleran Sunan Kudus dapat disaksikan hingga kini berupa peninggalannya berupa Masjid AlAqsha dan Menaranya. Menurut Rokhman, keunikan Masjid Al-Aqsha, pintu masuk menyerupai pintu masuk bangunan agama Hindu dan tempat wudlunya unik karena air wudlu keluar memancar dari mulut kalamakara sebagai akulturasi antara Islam dengan Hindu (Rokhman, 2014). Peninggalan bersejarah Sunan Kudus di Kawasan Menara Kudus antara lain berupa Menara yang memiliki keserupaan dengan candi. Hal ini dapat dipahami hasil riset Trisnayanti bahwa struktur bangunan candi terdiri tiga bagian, kaki/dasar candi, tubuh candi, dan atap (Trisnayanti, 2015).
Ketiganya terdapat di Menara Masjid AlAqsha Kudus. Hanya saja, candi atapnya terdapat stupa, sedangkan Menara peninggalan Sunan Kudus atapnya berupa bentuk limas. Menurut Zuhroh, Menara peninggalan Sunan Kudus menyerupai pura Hindu, gapuranya berbentuk Candi Bentar dan kori agung, bentuk ornamen padasan (tempat wudlu) bercorak kala dalam Buddha (Zuhroh, 2018).

Fakta dapat disaksikan pada tradisi buka luwur (selanjutnya disingkat BL) di Makam Sunan Kudus, pendakwah di Pulau Jawa era Wali Songo yang dilestarikan oleh muslim ala nahdliyin (diwadahi dalam ormas Nahdlatul Ulama/NU) maksudnya, muslim yang kehidupannya merawat ajaran Islam dan merespon tradisi lokal. Warga NU memiliki kepedulian pada leluhur yang telah berjasa dalam syiar Islam dengan mengenangnya dalam forum khoul (memperingati hari wafatnya tokoh muslim, lazimnya setiap tahun sekali). Khoul merupakan ekspresi kecintaan generasi penerus atas jasa generasi pendahulu dalam forum berdoa secara kolosal dengan berziarah di makamnya.

Tradisi BL (kain berwarna putih yang sehari-harinya melingkari makam Sunan Kudus) diganti luwur baru setiap bulan Muharam/Sura dalam tradisi peringatan hari wafat Sunan Kudus (khoul). Hanya saja, karena hari, tanggal, bulan, dan tahun wafatnya Sunan Kudus belum diketahui secara pasti, sejak kapan diselenggarakannya pun belum diketahui, tradisi ini disebut tradisi BL, bukan khoul. Tradisi ini diselenggarakan oleh masyarakat Desa Kauman, Kecamatan Kota, Kabupaten Kudus, Jawa Tengah dimotori oleh Yayasan Masjid, Menara, dan Makam Sunan Kudus (YM3SK). Bagi warga Desa Kauman (dalam konteks lokus ini, warga Kudus lebih familier menyebut Kauman Menara) karena keberadaan Menara di halaman depan Masjid al-Aqsha Kudus, di belakang Masjid al-Aqsha terdapat kompleks Makam Sunan Kudus. Kawasan ini, dalam perspektif kebudayaan 
disebut Kawasan Menara Kudus yang menjadi situs budaya peringkat nasional oleh Pemerintah Provinsi Jawa Tengah berdasarkan nomor inventaris 1119/Kud/01/TB/04.

Para penulis telah mengkaji topik ini, sebagaimana Fathurohman dan Setiawan bahwa BL Sunan Kudus mengandung makna dan simbol nilai luhur dan nilai edukatif dengan rasa toleran, saling menolong dan menghargai, melatih dan membiasakan bersedekah, mendekatkan diri pada Tuhan, dan membina budi pekerti luhur (Fathurohman dan Deka, 2017). Adapun Argarini dalam risetnya menandaskan bahwa BL Sunan Kudus memiliki makna kepedulian antarsesama dan adanya BL Sunan Kudus akan membuka ruang kebersamaan (Argarini, 2015). Penelitian serupa dilakukan oleh Reynal dkk bahwa yang melatarbelakangi warga Kudus melakukan ritual BL karena motivasi beragama, menghormati Sunan Kudus, berderma, dan kepuasan batin (Falah, 2017). Adapun nilai yang melekat dalam tradisi BL makam Sunan Kudus menurut Khotimah adalah mempertahankan larangan menyembelih sapi bagi warga Kudus sebagai wujud penghormatan pada umat agama lain sehingga nilai yang masih ada berupa religi, toleransi, ekasila, dan enkulturasi berupa pendidikan, kirab dandangan, dan kesenian terbang papat (Khotimah, 2018).

Akan tetapi, artikel ini menelaah eksistensi dan memprediksi keberlanjutannya sehingga berbeda dengan telaah para peneliti tersebut. Adapun faktor yang melatarbelakangi ditulisnya naskah ini adalah pertama, warga Kudus dan Pengurus YM3SK hingga era millennial ini tetap mempertahanan tradisi. Padahal, YM3SK belum mengetahui secara pasti tanggal wafatnya Sunan Kudus, tetapi mengganti luwur (kain yang melingkar di Makam Sunan Kudus) diganti setiap bulan Sura/Muharam. Mentradisikan atas dasar melanjutkan tradisi yang sudah ada tanpa mengubah tanggal dan rangkaian acara. Kedua, acara khoul ini memiliki kekhasan yakni sajian nasi siap saji dengan ragam sebutan nasi jangkrik, sego jangkrik (sego dalam bahasa Jawa bermakna nasi), nasi/sego berkat yakni seporsi nasi siap saji yang lauknya daging kerbau atau kambing (berasal dari sedekah donatur) dibungkus daun jati sejak dulu hingga kini. Dipilihnya daging kerbau atau kambing karena masih melanggengkan pesan Sunan Kudus (melalui tradisi tutur) yang melarang warga Kudus menyembelih sapi karena sapi hewan yang dihormati umat Hindu yang hidup di Kudus lebih dulu (sebelum Sunan Kudus di Kudus). Ketiga, artikel ini menelaah eksistensi dan memprediksi keberlanjutan acara BL. Dengan demikian, naskah ini memiliki aspek kebaruan telaah.

\section{METODE PENELITIAN}

Sebagai penelitian sejarah, riset ini menggunakan metode sejarah. Tahaptahapnya terdiri heurisik, kritik, interpretasi, dan historiografi. Langkahnya, menggali sumber data, data dikritisi untuk mendapatkan kebenaran data, data yang benar ditafsiri/dipahami dan ditulis. Dengan metode sejarah, penelitian ini diharapkan dapat merekonstruksi peristiwa masa lalu untuk dijadikan 'spion' membangun Kawasan Menara Kudus masa kini. Pertama, tahap heuristik adalah menemukan dan menghimpun sumber, informasi, dan jejak masa lalu (tahap menggali data sejarah). Kedua, tahap kritik adalah menilai keabsahan sumber, otentisitas/keaslian sumber (kritik eksternal), meneliti kredibilitas sumber sejarah (kritik internal). Ketiga, tahap interpretasi atau menafsirkan fakta sejarah yang telah terkumpul dalam tahap heuristik. Tanpa penafsiran dari sejarawan, fakta tidak dapat berbunyi. Keempat, tahap penulisan sejarah (historiografi) dengan memperlihatkan proses seleksi, imajinasi, dan kronologi (Kuntowijoyo, 2008). 
Strategi menggali sumber sejarah menuru Wasino (2007) dilakukan dengan (1) penelusuran bibliografi (membaca buku yang relevan dengan topik), (2) penelusuran sumber sejarah secara mendalam berupa sumber primer dan sekunder berupa rekaman sezaman, rekaman stenografis dan fonografis, suratsurat, buku catatan pribadi, laporan konfidensial (berita resmi militer, jurnal/buku harian, surat pribadi), (3) penelusuran laporan umum (dibaca oleh pembaca dalam jumlah lebih banyak dibanding laporan konfidensial), (4) pencarian berita surat kabar, (5) pembagian kuesioner tertulis, (6) pengumpulan dokumen pemerintah (UU atau peraturan), (7) sumber lisan, (8) sumber lain (artefak dan sumber audiovisual) (2007). Dari kedelapan sumber tersebut yang diperoleh penulis berupa referensi/pustaka, sumber lisan, dan sumber visual. Agar data lebih fokus, riset dengan metode sejarah ini menggunakan pendekatan sosiologi. Menurut Rachmad, sosiologi akan meneropong segi sosial peristiwa yang dikaji, seperti peran sosial, nilai sosial, dan hubungan antargolongan (2009). Penulisan sejarah bersifat apa adanya (wie es eigentlich), tunduk/patuh pada fakta, berintegritas (dedikasi/pengabdian), dan objektif. Ketiga karakter tersebut bagian dari kejujuran sejarawan dalam berkarya, sebagaimana karakter ilmuwan. Hal tersebut akan tercapai bila sejarawan memahami aspek kausalitas (sebabakibat) dalam peristiwa sejarah. Kausalitas muncul dengan memahami kasus (peristiwa) dan perubahan kasus. Teori yang digunakan dalam menulis sejarah berupa konjungtif (menghubungkan) antar-data, disjungtif (mencari alternatif) dalam menggali sumber data, rasional, deskriptif dalam memaparkan data sejarah, evaluatif, yakni mengevaluasi kebenaran data sejarah, dan kombinasi antar-data (Pranoto, 2006).
Kaidah penulisan sejarah mempertimbangkan regularitas (keajegan, keteraturan, dan konsistensi), generalisasi (kesamaan karakteristik tertentu), memahami pembagian atau pembabakan waktu sejarah (berubah cepat, lambat, dan tidak berubah), dan multiinterpretable (menafsirkan, mengerti, dan memahami peristiwa sejarah) (Kuntowijoyo, 2011). Pembabakan waktu sejarah dapat dibagi menurut aliran politik yang melahirkannya berupa politik kolonial kolot, politik kolonial progresif, politik ekonomi, dan politik kebangsaan (Ali, 2005). Hal/ peristiwa dipandang bernilai sejarah bila memiliki penjelasan sejarah dengan prinsip (1) menafsirkan (hermeneutics) dan mengerti (verstehen), (2) waktu yang memanjang, dan (3) peristiwa tunggal. Penjelasan sejarah tersebut didukung oleh data yang otentik, tepercaya, dan tuntas. Kaidah eksplanasi sejarah yakni adanya reguleritas dan generalisasi. Pertama, reguleritas (keajekan, keteraturan, konsistensi) sebagai cara menjelaskan hubungan sebab-akibat (kausal) antarperistiwa sejarah. Kedua, generalisasi yakni adanya persamaan karakteristik atas peristiwa sejarah. Ketiga, adanya simpulan. Keempat, pembagian waktu yakni jangka panjang atau pendek, meskipun ukuran waktu tidak kaku batasannya. Kelima, pemaparan data sejarah dapat berupa narasi atau deskripsi (Kuntowijoyo, 2008). Menurut Gottschalk, sejarawan setidaktidaknya mempunyai dua tujuan dalam menulis sejarah yakni pengawal warisan budaya dan penutur kisah (Gottschalk, 1975). Naskah ini menggambarkan pentingnya melestarikan atau mengawal warisan budaya.

\section{HASIL DAN PEMBAHASAN \\ Rangkaian Acara Tradisi Buka Luwur Makam Sunan Kudus}

Makam Sunan Kudus berada di kompleks bagian belakang Masjid al-Aqsha Menara Kudus. Cungkup makam Sunan Kudus terdiri nisan, jirat, ranjam, dan 
fitrage yang dilepas secara berurutan. Kompleks makam di antaranya terdiri Makam Sunan Kudus, keluarganya dan orang dekatnya, serta pejabat Kudus masa lalu. Makam Sunan Kudus panjangnya 225 $\mathrm{cm}$, dengan lebar $70 \mathrm{~cm}$, ketinggiannya 40 $\mathrm{cm}$, batu nisan tingginya mencapai $68 \mathrm{~cm}$, dengan lebar $14 \mathrm{~cm}$. Ada 8 cungkup (bangunan pelindung makam) di kompleks pemakaman Sunan Kudus. Menurut Salam, kompleks Makam Sunan Kudus terdiri atas tiga pilahan (1) keluarga Sunan Kudus, yakni putra Sunan Kudus dengan isteri keduanya dikaruniai 8 anak antara lain Adipati Pecat Tanda Terung, putri Pangeran Husen, seibu dengan Raden Patah dari Majapahit. Kedelapan putra Sunan Kudus hanya 4 yang dimakamkan di Kompleks Sunan Kudus. Keempatnya, Panembahan Palembang, Panembahan Mekaos Honggokusumo, Pangeran Poncowati, dan Pangeran Sujoko (wafatnya tatkala masih muda). Adapun makam yang belum terdeteksi dan berada di lingkungan kompleks Makam Sunan Kudus, yakni Nyi Ageng Pembayun, Panembahan Kodhi, Panembahan Karimun, Ratu Probobinabar (panglima perang), Panembahan Kuleco, dan Ratu Pakojo (Salam, 1986). (2) Kompleks orang dekat Sunan Kudus, yakni Pangeran Pedamaran I s.d V, dan (3) kompleks pejabat tinggi di Kudus era pra dan masa kolonial, yakni K.H.R Padmonegoro (mantan Bupati Kudus, menantu Susuhunan Paku Buwono III era 17491788), R.Ayu Tjondrohadinegoro, R.Ayu Tisnowijoyo Patih Tumenggung, KRT Tjokrohadinegoro, R.Ayu Ng.Sumodiprojo, RM Pratisna Suryakusumo, R.Bagus Sutikna Tjokronegoro, Penghulu Bedogas, dll.(Salam, 1977). Kompleks makam Sunan Kudus kini tidak lagi digunakan untuk pemakaman karena area makam telah penuh. Sosok yang terakhir dimakamkan di kompleks makam tersebut adalah K.H.R.Asnawi, keturunan ke 12 Sunan Kudus. Keturunannya hingga kini berada di Kawasan Kauman Menara Kudus pada urutan trah ke-13, keturunan ke-12 adalah almarhum Kiai/Raden Asnawi. Dalam catatan Hana, dkk (2017) silsilah R.Asnawi hingga Sunan Kudus secara berurutan dari atas ke bawah yakni Ja'far Shodiq (Sunan Kudus), Panembahan Palembang, Pangeran Gemiring, Pangeran Pengaringan, Pangeran Pedamaran I dan II, Raden Ngabehi Condro Paruna, Raden Dipoyudo, Raden Puspo Kusumo, Nganten Salamah, Nganten Sofiyah, Raden Abdullah Husnin, dan Asnawi lahir tahun 1281 H/1861 M di Desa Damaran, Kecamatan Kota, Kudus. Raden Asnawi merintis Madrasah Qudsiyah tahun 1917 M dan pendiriannya tahun 1919 M/1337 H hingga kini. R.Asnawi wafat pada Sabtu Kliwon 25 Jumadil Akhir 1379 H/26 Desember 1959 dimakamkan di kompleks Makam Sunan Kudus, tepat di belakang Masjid Al-Aqsha Menara Kudus (Hana, dkk., 2017). Rangkaian acara BL diagendakan oleh Yayasan Menara Kudus, sebagaimana tabel acara tahun 2019 $\mathrm{M} / 1441 \mathrm{H}$ tertuang dalam lampiran. Kekhasan tradisi BL menjadi daya tarik bagi publik karena tidak selalu ada pada acara serupa di Kudus.

Pertama, pembagian Bubur Asyura pada warga se-Desa Kauman dari rumah ke rumah oleh panitia. Kisah tertradisinya Bubur Asyura terinspirasi oleh sejarah terselamatkannya Nabi Nuh dan umatnya akibat banjir yang melumat kehidupan era itu. Pascasurutnya banjir, tanggal 10 Sura (Asyura) dilakukan doa dengan menghidangkan bubur. Bubur Sura pada acara BL Makam Sunan Kudus dibuat pada 9 Sura oleh panitia acara BL. Pelaksanaan memasak bubur selama tiga jam yang bahan bakunya meliputi 9 item, beras, jagung, kacang hijau, kacang kedelai, kacang tolo, ketela pohon, kacang tanah, pisang, dan ubi jalar. Ragam menu yang disajikan berupa bubur berwarna putih, potongan/irisan meliputi tahu dan tempe, telur dadar, cabe, udang, pelas, ikan teri yang diletakkan pada piring yang dilapisi dengan daun pisang. Kedua, pembagian 
berkat atau nasi jangkrik (nasi siap saji dibungkus daun jati dengan lauk daging kerbau atau kambing, bukan sapi) sebagai simbol visual sedekah dan pesan peduli terhadap sesama (Argarini, 2015). Tidak menggunakan daging sapi tapi kerbau atau kambing sebagai menu dalam nasi jangkrik mewarisi pantangan Sunan Kudus agar warga Kudus tidak memotong sapi karena sapi sebagai hewan yang dikeramatkan umat Hindu. Ketiga, pembagian kain luwur. Kain luwur di Makam Sunan Kudus berwarna putih, setiap harinya menutup/melingkari makam dan setiap tahun/bulan Muharam diganti kain baru. Kain luwur lama diberikan secara cumacuma hanya bagi warga Desa Kauman dan pada tamu undangan yang mendapat nasi jangkrik (pada acara puncak) pada puncak acara BL. Kain tersebut dipotong-potong dengan ukuran per potong kurang lebih panjang $20 \mathrm{~cm}$. Luwur oleh warga penerima digunakan ragam kepentingan sesuai keyakinannya setelah terkumpul dalam beberapa tahun (mendapatkan luwur tiap 10 Sura). Ada yang untuk membungkus keris, surban, baju koko, dan, sleyer (rida). Ada pula yang hanya disimpan di dompet, di rumah, atau pembungkus potongan tali pusar (ari-ari) bayi pascadilahirkan. Ada pula dijadikan media penunduk kerbau yang tali pengikatnya lepas ketika disembelih. Caranya dengan memegang luwur dihadapkan pada kerbau (Rosyid, 2018). Pemanfaatan luwur tersebut berdasarkan keyakinan si pemilik bahwa luwur ketika melingkari Makam Sunan Kudus selalu 'disirami' bacaan doa peziarah makam.

Ragam motif luwur di Makam Sunan Kudus meliputi bunga melati, unthuk banyu, kompol, dan wiru. Bunga melati bermakna kesucian dan keagungan. Jadi, motif luwur berupa bunga melati diharapkan Makam Sunan Kudus disucikan karena tempat yang agung. Motif unthuk banyu bermakna tempat yang dapat dijadikan berdoa kepada Allah swt agar dimudahkan sumber perekonomian pendoa dengan perantara (wasilah) Sunan Kudus. Adapun motif wiru atau wiron merupakan motif/bentuk lipatan laksana bentuk kipas tangan di ujung kain luwur. Membuat wiru/wiron membutuhkan kesabaran yang tinggi. Dengan demikian, bagi peziarah, dalam berdoa membutuhkan kesabaran agar doa dikabulkan Allah swt.

Ke-12 rangkaian acara Buka Luwur (terlampir) hanya ketiga acara tersebut yang memiliki kekhasan yang direspon oleh publik secara luas dan tak terbatas jumlahnya. Adapun rangkaian acara lain kurang direspon secara luas oleh publik karena kegiatan/acara ada juga di tempat lain, tidak hanya pada acara Buka Luwur Sunan Kudus seperti Pengajian Tahun Baru Hijriyah, Munadharah Masail Diniyah, Doa Rasul dan Terbang Papat, Khotmil Quran bil Ghoib, Santunan Yatim Piatu, Pembacaan Qasidah al-Barzanji. Adapun acara khas pada acara BL Sunan Kudus tapi kurang direspon publik yakni penjamasan Pusaka Cintoko dan Pelepasan Luwur Makam Sunan Kudus karena publik tidak mendapat 'imbalan' sesuatu dari kedua acara tersebut. Berbeda dengan pembagian bubur sura, nasi berkat, dan puncak perayaan Buka Luwur mendapat sego jangkrik dan bagi tamu undangan juga mendapatkan potongan kain luwur, ketiganya warga mendapatkan dari panitia secara gratis.

\section{Memprediksi Keberlanjutan Tradisi Buka Luwur}

Untuk memperoleh jawaban dalam memprediksi keberlanjutan tradisi BL di Makam Sunan Kudus, perlu dipahami perihal Kota Kudus dan Desa Kauman, Kecamatan Kota, Kudus. Memahami lokus di mana acara dilaksanakan penting dipahami. Kota Kudus didirikan pada tanggal 2 Oktober 1549 bersumber dari Prasasti Condro Sengkolo Lombo di atas mihrab Masjid Menara Kudus. Pada prasasti itu tertulis "Bismillahirrahmanirrahim. Aqaama bina 
al masjid al Aqsha wal al balad al Quds khalifatu haadzad dar habru (aali) Muhammad yasytari (?) izzan fi jannah alkhudi...quran min arrahman bibalad al Quds (?) Ansya-a haadza masjid al Manar (?) al musamma bi Aqsha khalifatullahi fil ardli al-'ulyaa wa al mujtahid as-sayyid al 'arif al kamil al fadhil al maksus bi 'inayati...al qaadhi Jafar as Shodiq ...sanah sittin wa khomsiina wa tis'in mi'atin al hijr $(959$ H) annabawiyyah. Bila diindonesiakan "Dengan nama Allah yang Maha Pengasih dan Maha Penyayang. Telah mendirikan masjid al-Aqsha ini di negeri Kudus, khalifah pada zaman ulama dari keturunan Muhammad untuk membeli kemuliaan surga yang kekal, untuk mendekat Allah di negeri Kudus. Membina masjid al-Manar yang dinamakan al-Aqsha khalifatullah di bumi, yang agung dan mujtahid yang arief, kamil fadhil al-maksud dengan pemeliharaan al-Qodli Ja'far Shodiq tahun 956 hijrah Nabi SAW" (Hassan dan Maesah, 2015). Hal ini diperkuat oleh Ludvik Kalus dan Claude Guillot dalam bukunya Kota Yerussalem di Jawa Masjidnya Al-Aqsa dalam Inskripsi Islam Tertua di Indonesia (Kalus dan Guillot, 2008).

Hanya saja, sebelum ada nama Kota Kudus, wilayah tersebut telah dihuni umat Hindu dengan bukti hingga kini berupa adanya Sanggar Bubrah (SB) yakni benda cagar budaya yang terdapat lingga dan yoni. SB merupakan bangunan kuno yang kondisi bangunannya kini sudah lapuk karena kurang kepedulian Pemkab Kudus. Mengidentifikasi jejak SB dapat diawali dengan memahami karakter situs peninggalan Hindu. Situs yang memiliki karakter peninggalan Hindu dapat berupa (1) yoni, (2) lingga, (3) kori (pintu dalam dan luar bangunan pura), (4) balai tajug yakni bangunan di area bagian terluar pura/setelah kori (berfungsi rapat keagamaan, tempat membuat sajen, dan tempat sajen. Keempat ciri tersebut, di SB ada lingga dan yoni hingga kini. Sanggar Bubar dari sanggar (tempat memuja/pemujaan) dan bubrah bermakna bangunan yang belum tuntas dibangun. Tetapi, kata Sanggar Bubrah diubah menjadi Langgar Bubrah/LB. Kata langgar bagi orang Jawa adalah musala/tempat ibadah salat dan Bubrah adalah bangunan yang tidak sempurna atau belum jadi.

Dalam Hindu lingga dan yoni merupakan simbol sebagai media berdialog hamba dengan Tuhan (Sang Hyang Widi Wase) dan sarana mendekatkan diri pada Tuhan. Riset Hastutiningsih, Candi Sukuh sebagai tempat yang disucikan/disakralkan umat Hindu memiliki beberapa simbol sebagai manifestasi Dewa yang diagungkan. Simbol yang paling nampak adalah lingga dan yoni yakni lambang Dewa Syiwa, lambang kesuburan. Simbol yoni dan lingga tersebut dilingkari dengan yoni berantai bunga sebagai makna pentingnya ikatan perkawinan dan hubungan seks (suamiisteri) merupakan suatu yang sakral (suci). Kedua simbol tersebut juga difungsikan untuk media pengobatan (Hastutiningsih, 2008). Riset tersebut menandaskan bahwa lingga dan yoni merupakan simbol utama yang ada di tempat suci umat Hindu. SB/LB di Dukuh Tepasan, Desa Demangan, Kecamatan Kota, Kabupaten Kudus.

Ditemukan candi Hindu Mini di Dukuh Ngemplik, Desa Bacin, Kecamatan Bae, Kudus. Panjang candi $4 \mathrm{~m}$, berdiameter $4 \mathrm{~m}$, tinggi $140 \mathrm{~cm}$, di persawahan seluas 0,5 ha, luas bangunan berdenah segi empat seluas $16 \mathrm{~m}$ persegi. Bahan candi dari batu bata merah, panjang bata $4 \mathrm{~cm}$, lebar $20 \mathrm{~cm}$, tebal $11 \mathrm{~cm}$. Candi diprediksi era abad 8-9 M era Hindu Syiwaistis. Awalnya candi ditemukan warga Desa Bacin, Suwarno ketika menggali lahan sawahnya pada 22 Agustus 1990. Awalnya diduga bekas makam China (bong chino). Oleh Balar Yogyakarta dilakukan eskavasi, struktur bangunannya segi empat dengan ukuran $4 \times 4 \mathrm{~m}$, digali pada kedalaman $140 \mathrm{~cm}$ dari permukaan tanah. Komplek candi terdapat (a) yoni terbuat dari batu kapur berwarna putih 
yang kondisinya pecah menjadi dua bagian. Panjang yoni $44 \mathrm{~cm}$, lebar $44 \mathrm{~cm}$, tinggi $35 \mathrm{~cm}$, dengan lubang di tengah berbentuk segi empat dengan ukuran $10 \times 10 \mathrm{~cm}$, (b) kemuncak I di dekat yoni, kemuncak terbuat dari terakota yang kondisinya aus seluruh permukaannya, ada lubang-lubang kecil dan goresan bekas benda tajam. Kemuncak terdiri tiga bagian yakni kaki, tubuh, dan puncak dan semuanya dengan sisi yang sama berisi 8 . Pada bagian puncak mengarah ke bentuk bulat lojong, panjang $24 \mathrm{~cm}$, lebar $24 \mathrm{~cm}$, tinggi $46 \mathrm{~cm}$ dengan diameter atas $20 \mathrm{~cm}$. Kemuncak II , bagian kaki dan tubuh berbentuk segi empat, pada keempat sisi bagian tubuh terdapat relung persegi empat yang diukir, kondisinya relatif utuh, meski permukaannya mengalami keausan, panjangnya $24 \mathrm{~cm}$, lebar $4 \mathrm{~cm}$, tinggi 35 $\mathrm{cm}$. Kini, Candi disimpan di Museum Ronggowarsito Semarang yang dikelola oleh Dinas Kebudayaan dan Pariwisata Jawa Tengah karena di Kudus belum ada tempat penyimpanan yang layak.

Benda purbakala di lingkungan masjid berupa (1) dua gapura kembar gaya Hindu di serambi dan di dalam masjid (awalnya benteng pelindung masjid era kewalian), dan gapura padureksan (di halaman masjid), gapura samping masjid, gapura tajug (sisi samping belakang masjid). Panjang gapura kembar $548 \mathrm{~cm}$, lebar $272 \mathrm{~cm}$, tinggi $625 \mathrm{~cm}$, lebar pintu $116 \mathrm{~cm}$ tinggi $271 \mathrm{~cm}$. Gapura kembar bagian dalam merupakan pintu masuk masjid. Di sana juga terdapat menara berukuran $10 \mathrm{~m}$, tinggi $18 \mathrm{~m}$, terbuat dari batu bata merah, sirap, dan perekat batu bata dengan susunan selasar batu, kaki, tubuh bangunan dan atap. Pada bagian kaki (dasar) menara terdapat ornamen geometrik berupa batu hiasan segi empat yang setiap ujungnya disambung hiasan segi tiga. (2) Tempat wudu (padasan) terdiri 8 pancuran (kran) hingga kini masih utuh. (3) Tajug, tempat musyawarah Sunan Kudus (masa kini, khususnya bulan Ramadan digunakan untuk mengaji kitab kuning di sore hari) dan tempat menyimpan keris dan tombak Sunan Kudus dalam peti.

Keberlanjutan tradisi buka luwur akan lestari karena, pertama, berziarah, khoul/buka luwur merupakan acara penghormatan pada tokoh yang berdakwah. Acara tersebut masih diyakini warga Kudus sebagai ibadah. Kedua, daya rekatnya berupa bubur Sura, nasi jangkrik/nasi berkat, dan kain luwur yang diberikan secara gratis kepada warga Desa Kauman dan tamu undangan yang diundang tertulis dan tidak tertulis merupakan acara yang ditunggu warga. Ketiga, tradisi memiliki nilai adiluhung. Menurut Handoyo, dkk, fungsi nilai untuk kehidupan manusia (1) sebagai faktor pendorong, cita-cita, harapan, (2) petunjuk arah, cara berpikir, berperasaan, dan bertindak, dan (3) alat pengawas dengan daya tekan dan pengikat tertentu (Handoyo, dkk, 2015). Budaya BL sejalan dengan konsep nilai menurut Handoyo meliputi nilai material, vital, dan kerohanian karena makna penghormatan pada Sunan Kudus. Panitia dan warga menjadikan tradisi BL sebagai media haul pada Sunan Kudus dan diyakininya menjadi kewajiban memperingati. Ada pula konsep nilai versi Notonagoro meliputi (1) material yakni berguna untuk klangsungan kehidupan manusia, (2) vital yakni berguna untuk aktifitas kehidupan, (3) kerohanian yakni berguna untuk rohani manusia. Nilai ini terbagi atas (a) nilai kebenaran yang bersumber dari rasio/akal, budi, cipta manusia, (b) nilai keindahan/estetis yang bersumber dari perasaan seseorang, (c) nilai kebaikan/moral yang bersumber pada unsur kehendak manusia, dan (d) nilai religius yakni nilai rohani yang tertinggi/mutlak (Notonagoro dalam Suyahmo, 2014). Nilai dalam BL khususnya pembagian Sego Berkat merujuk konsep nilai oleh Notonagoro tersebut, nilai yang terkandung dalam tradisi pembagian sego berkat (1) nilai 
material yakni makanan yang berguna untuk bahan konsumsi primer warga yang menerima, (2) nilai vital yakni kegunan aspek terbatas hanya setiap bulan Muharam/Sura saja, (3) kerohanian yakni berguna untuk pemantapan rohani tamu yang menghadiri untuk menghormati Sunan Kudus. Nilai ini kental bermuatan nilai religius yakni nilai kebutuhan rohani.

Nasi berkat dalam tradisi ini pun memiliki makna sebagai makanan yang mengandung unsur tradisi, sedangkan bungkus daun jati sebagai simbol sandang. Antusiasme panitia, berpantangan meminta sumbangan tetapi respon publik antusias memberi sedekah atas inisiatif sendiri untuk keperluan acara BL dan warga pun responsif menghadirinya, baik yang diundang tertulis maupun tidak diundang tertulis. Ada keyakinan, bila nasi yang dimasak panitia habis diterimakan pada tamu dan publik yang menghadiri acara BL dianggap pertanda warga Kudus menghadapi sandang pangan murah (sejahtera), tetapi bila kekurangan maka harga pangan akan mahal (Argarini, 2015). Sugesti ini didominasi nilai rohani bagi panitia dan warga.

\section{SIMPULAN}

Tradisi buka BL Makam Sunan Kudus di Kawasan Menara Kudus Jawa Tengah sebagai wujud penghormatan warga Desa Kauman khususnya dan warga Kudus yang dimotori oleh Pengurus Masjid, Menara, dan Makam Sunan Kudus (YM3SK) setiap bulan Muharam. Ada 12 rangkaian kegiatan setiap tahun tanpa perubahan. Keberlanjutan tradisi ini diprediksi akan tetap lestari karena ada unsur ajaran agama (ziarah kubur dan mendoakan leluhur). Hal yang perlu dirawat Pemkab Kudus bersama masyarakat Kudus adalah benda cagar budaya yang bernilai sejarah ditemukan di Kudus. Benda tersebut berupa yoni, lingga, dan candi sebagai fakta bahwa Kudus pra-Islam ada kehidupan umat Hindu.

\section{DAFTAR PUSTAKA}

Ali, R.M. (2005). Pengantar Ilmu Sejarah Indonesia. Yogyakarta: LKiS.

Argarini, M. (2015). Persepsi Masyarakat Kudus terhadap Simbol Visual pada Tradisi Buka Luwur Sunan Kudus. Skripsi Jurusan Ilmu Komunikasi UNS Surakarta. 2015.

Fathurohman, Irfai, E.A.I. dan Setiawan, D. (2017). Makna dan Nilai Buka Luwur Sunan Kudus (Sumbangan Pemikiran Mewujudkan Visi Kampus Kebudayaan. Kredo Jurnal Ilmiah Bahasa dan Sastra Universitas Muria Kudus, Vol.1, No 1.

Falah, R, dkk. (2017). Motivasi dan Nilai Hidup Masyarakat Kauman dalam Melakukan Ritual Adat Buka Luwur di Makam Sunan Kudus. Indegenous Jurnal Ilmiah Psikologi Universitas Muhammadiyah Surakarta.

Gottschalk, L. (1975). Mengerti Sejarah, terjemahan Nugroho Notosusanto. Jakarta: Universitas Indonesia Press.

Hastutiningsih, T. (2008). Simbol-Simbol Agama Hindu di Candi Sukuh (Studi Simbol Agama Hindu di Dusun Sukuh, Kecamatan Ngargoyoso, Kabupaten Karanganyar, Jawa Tengah. Skripsi UIN Sunan Kalijaga Yogyakarta.

Handoyo, E, dkk. (2015). Studi Masyarakat Indonesia. Unnes Press: Semarang.

Hassan, E.N. dan Anggni, M. (2015). Menara Menjaga Tradisi Nusantara. YM3SK: Kudus.

Hana, M, dkk. (2017). Jejak Ulama Nusantara Menelusuri Hikmah dan Hikayat Tokoh Islam di Kudus. Aqila Quds: Kudus.

Hasanah, U. (2019). Respon Masyarakat Kudus terhadap Strategi Dakwah Sunan Kudus. Skripsi IAIN Salatiga.

Isrofah. (2018). Ragam Pemaknaan Nasi Uyah Asem Menurut Masyarakat Desa Getasrabi, Kecamatan Gebog, Kudus. Skripsi Fakultas Ushuluddin dan Humaniora UIN Walisongo Semarang.

Kuntowijoyo. (2001). Pengantar Ilmu Sejarah. Bentang: Yogyakarta.

Kuntowijoyo. (2008). Penjelasan Sejarah. Tiara Wacana: Yogyakarta.

Khotimah, N. (2018). Enkulturasi Nilai-Nilai Kesejarahan Sunan Kudus pada Masyarakat di Daerah Kudus Kulon. Historia Pedagogia Jurnal Penelitian dan Inovasi Pendidikan Sejarah Unnes Semarang, Vol.7, No.2.

Pranoto, S.W. (2006). Teori dan Metodologi Sejarah. Graha Ilmu: Jakarta.

Rochmat, S. (2009). Ilmu Sejarah dalam Perspektif Ilmu Sosial. Yogyakarta: Graha Ilmu.

Rokhman, N. (2014). Perpaduan Budaya Lokal, Hindu Buddha, dan Islam di Indonesia. Diktat Prodi Pendidikan Sejarah FIS Universitas Negeri Yogyakarta. 
Moh Rosyid, Pelestarian Tradisi Buka Luwur: Studi Budaya di Makam Sunan Kudus Jawa Tengah

Rosyid, M. (2018). Mempertahankan Tradisi: Studi Budaya di Kampung Kauman Menara Kudus. Jurnal Patanjala Vol.11, No.2, 2019.

Salam, S. (1986). Ja'far Shadiq Sunan Kudus. Menara Kudus: Kudus.

Salam, S. (1986). Kudus Purbakala dalam Perjuangan Islam. Menara Kudus: Kudus.

Suyahmo. (2017). Filsafat Moral. Fakultas Ilmu Sosial Unnes: Semarang.

Trisnayanti, C. (2015). Studi Bentuk dan Makna Relief Candi Sojiwan. Skripsi Fakultas Seni
Rupa dan Desain Institut Seni Indonesia Surakarta.

Wasino. (2007). Dari Riset Hingga Tulisan Sejarah. Semarang: Unnes Press.

Zuhroh, M. (2018). Masjid Menara Kudus: Ekspresi Multikulturalisme Sunan Kudus Studi Kasus Kehidupan Toleransi Masyarakat Kudus. Skripsi Jurusan Studi Agama Fakultas Ushuluddin UIN Jakarta. 